\section{Enseñanza y aprendizaje de la Geografía para el siglo XXI}

Rafael Sebastià Alcaráz y Emilia María Tonda Monllor (Editores)

Editorial: Publicaciones de la Universidad de Alicante (miembro de la Unión de Editoriales Universitarias Españolas); Alicante (España) (2017), 221 pág. (ISBN: 978-84-16724-47-5.).

DOI: http://dx.doi.org/10.19137/huellas-2018-2217

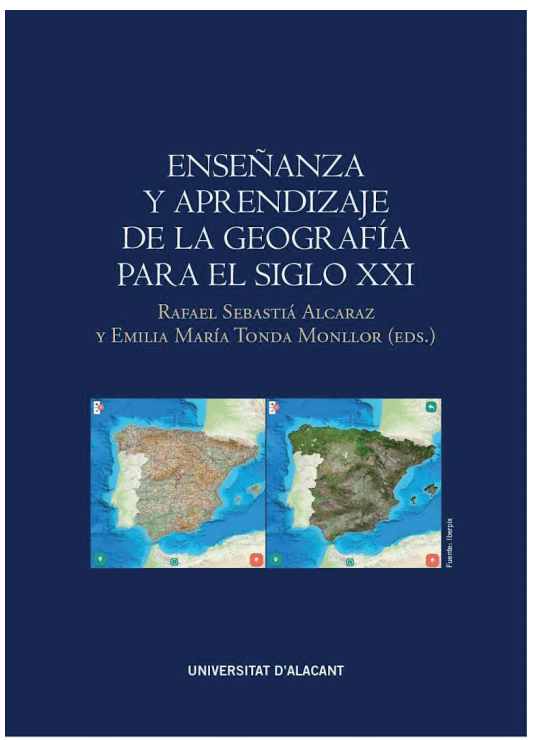

$\mathrm{D}$ esde la década de 1990 no se había publicado un libro de divulgación que recogiera las últimas actualizaciones en la didáctica de la geografía. Los coordinadores de esta obra (Rafael Sebastià y Emilia María Tonda) son dos referentes en la investigación en la didáctica geográfica, tal y como avalan sus publicaciones científicas en revistas especializadas y en congresos nacionales e internacionales. Ante los nuevos retos que demanda la sociedad global (o sociedad de la información y de las nuevas tecnologías) han creído conveniente reunir los aportes más relevantes en enseñanza y aprendizaje de la geografía, en un libro dirigido a estudiantes y docentes de enseñanzas medias para orientarles sobre recursos y métodos didácticos.

La estructura secuencial de esta obra de 221 páginas y cuatro capítulos es clara y precisa. La importancia de la enseñanza y el aprendizaje de la geografía se ha puesto de relieve en el primer capítulo realizado por Carmen Delgado Viñas, presidenta de la Asociación de Geógrafos Españoles. Como docente universitaria comienza destacando la importancia que ha adquirido el análisis territorial entre la sociedad actual, ya que la preocupación ciudadana por el territorio ha aumentado en paralelo a los cambios académicos que ha experimentado esta disciplina en la Sociedad del Conocimiento. Se habla del conocimiento del territorio o "Inteligencia Territorial" ya que la complejidad de las estructuras territoriales y sus dinámicas demandan un conocimiento específico que apueste por la sostenibilidad y la cohesión territorial desde una perspectiva multiescalar.

A esa nueva forma de pensar y actuar en el territorio está contribuyendo la geografía académica. Precisamente desde la Geografía (Harvey, Soja, Hall) como desde otras disciplinas afines (especialmente la sociología propugnada por Gidens y Castells) se refrenda el valor de la primera para interpretar la realidad contemporánea. Sin embargo esa transversalidad (de la que la geografía es la ciencia central) no se ha contemplado en ninguna reforma de los planes de estudios universitarios de geografía (ni en licenciaturas ni grados) en España. La denominación de los actuales grados universitarios de geografía es una expresión relevante de la preocupación práctica, aplicada y profesional de las nuevas estructuras académicas, en la que han colaborado los Colegios de Geógrafos. Aunque la doctora Delgado reconoce la es- 
casa preocupación concedida en los grados universitarios de geografía a la formación de docentes en niveles previos, finaliza su aportación reconociendo la necesidad de recuperar la profesionalización docente en igualdad de condiciones respecto de los geógrafos dedicados a la planificación territorial, la gestión territorial o los expertos en Sistemas de Información Geográfica.

Consecuentemente la investigación en didáctica de la geografía se ha realizado fundamentalmente por docentes de Educación Secundaria que se han preocupado por aunar investigación e innovación para mejorar la enseñanza y el aprendizaje de esta disciplina en el ámbito escolar (incluso con propuestas en Educación Infantil y Primaria). Un primer ejemplo de aproximación a la construcción del conocimiento geográfico (así lo han titulado sus autores en el segundo capítulo) es el tratamiento de las ideas previas y su influencia en el aprendizaje espacial. Rafael Sebastià y Emilia María Tonda han tomado como base los estudios de Aisenberg (1994) para trabajar la alfabetización geográfica del concepto de Andalucía desde una doble vertiente: el conocimiento de los atributos de este topónimo entre alumnos del Máster de Profesor de Educación Secundaria y el dominio general de la inclusión (escalas y redes geográficas) por el alumnado de segundo curso del grado de magisterio de la Universidad de Alicante. Han descubierto la gradación del aprendizaje de la inclusión espacial desde la Educación Primaria con la finalidad que este alumnado descubra categorías de rango superior y evite exclusiones derivadas de atributos en forma de prejuicios y estereotipos. En el segundo caso y en consonancia con los estudios de Constancio de Castro, la utilización de mapas mentales ha revelado cómo se estructura la información geográfica mediante categorías espaciales (proximidad, centro-periferia, lateralidad). Por tanto concluyen que di- chas categorías espaciales son la base para la construcción de redes geográficas sobre conceptos geográficos.

En la segunda parte del capítulo dos, el profesor Xosé Manuel Souto plantea que la enseñanza de la geografía requiere de un método para organizar el trabajo didáctico. Ese método es entendido como un proceso de investigación de un modelo de aprendizaje basado en las representaciones sociales del espacio (espacio vivido, percibido y concebido), que se inicia con el trabajo de las ideas espontáneas. Esas concepciones tienen que cuestionarse desde el ámbito escolar y ciudadano para desarrollar una cosmovisión a partir de la utilización de técnicas diversas como encuestas, comentarios de textos, juegos de simulación o narrativas sobre un tema concreto a partir de palabras que progresivamente les permitan abstraerse hacia el conocimiento geográfico. Tras conocer cómo interpreta la información geográfica (cartográfica, icónica, estadística y verbal) el alumnado está preparado para trabajar las cuatro competencias (las mismas que las tipologías de información mencionadas) mediante técnicas concretas (climogramas o comentarios de texto) que les permitan manipular los datos, convertirlos en hechos y presentar la información en diferentes tipologías textuales: textos narrativos en resúmenes, textos explicativos en síntesis y textos expositivos-argumentativos en informes. $\mathrm{La}$ convicción porque el método guíe la práctica escolar, le ha llevado a trasladar esos planteamientos metodológicos como aval de una práctica escolar experimentada por el proyecto Gea Clío, cuyos materiales didácticos presentan un planteamiento teórico y una reflexión sobre la praxis escolar para que cada docente adapte el método de trabajo a las necesidades y al contexto socio-escolar de su alumnado.

Con el modelo pedagógico del proyecto Gea Clío se aúna la investigación y 
la innovación en la práctica de la enseñanza de la geografía escolar. Esta es la reivindicación que realiza la profesora Lana de Souza Cavalcanti en el contexto brasileño, como cierre del segundo capítulo dedicado a la metodología docente. La autora comienza con una reflexión sobre la relevancia social de las investigaciones geográficas, de las que recoge que la sociedad es parte integrante del espacio geográfico. Con esta premisa pretende que la geografía escolar considere la percepción del alumnado en la construcción del espacio geográfico a partir de un proceso o método conducente a la solución del problema. Para ello analiza los obstáculos en la práctica docente y sintetiza una serie de indicaciones con la finalidad de que el trabajo en el aula considere el pensamiento espacial. Este planteamiento lo ilustra con cuestiones referidas al estudio de las migraciones en las que pretende consolidar conceptos estructurantes (paisaje, lugar, territorio) y sólidos, en la línea del sistema conceptual de Vigostky, frente a la dispersión de información vertida por la opinión pública.

La propuesta didáctica del profesor Jorge Olcina es una reflexión profunda por este investigador especializado en cuestiones climáticas y de tiempo atmosférico. Nadie mejor que este experto y reconocido científico nacional e internacional para analizar las dificultades que ofrece la enseñanza de estas dos cuestiones (tiempo y clima) en Educación Secundaria. Su capítulo (número III) comienza con una revisión del currículo en la que aparecen ambos conceptos (definición, elementos, factores) y cómo se plasma a diferentes escalas (Europa, España y la Comunidad Valenciana), que incluye algunas críticas fundamentadas (por ejemplo, la medida de la temperatura en grados Celsius y no en grados centígrados) y la discusión sobre el grado de adecuación de los contenidos en función del nivel educativo al que se han programado. Al mismo tiempo, acompaña el texto de recursos variados (gráficos, mapas, imágenes...) que ilustran su argumentación y dotan de mayor rigor a sus explicaciones. Finalmente establece una propuesta didáctica detallada sobre la enseñanza del tiempo y del clima tanto en Secundaria ( $1^{\circ}$ y $3^{\circ}$ ESO) como en segundo curso de Bachillerato, en la que presta especial atención al uso de fuentes, recursos y actividades variadas, incluso procedentes de la historia del arte (obras de arte con escenas de nubes).

$\mathrm{Al}$ actual contexto de Sociedad de la Información que comentaba Carmen Delgado al inicio, se añade el papel de la tecnología. De esta manera comprendemos la síntesis del doctor Alfredo Ramón Morte (capítulo IV, primera parte) profesor titular del departamento de Análisis Geográfico Regional y Geografía Física de la Universidad de Alicante. En el caso de los recursos geográficos, señala que la cartografía ha estado al servicio de la sociedad y se ha ido adaptando a los cambios en las formas de interpretar el territorio. Por ello se centra en el concepto Web-GIS, ya que los usuarios (sean especialistas en geografía o no) asumen el papel de residentes digitales, pues se ha producido una evolución en paralelo a la divulgación de los SIG. Este cambio en la forma de relacionarnos con la web ha provocado que en muy pocos años hayamos pasado de un web estática a una web dinámica que hasta a la Universidad ha tomado por sorpresa, ya que no se disponía del personal adecuado para digitalizar los recursos. El escenario futuro que plantea este docente, especializado en turismo, es la contribución de las tecnologías (sobre todo con la generalización del web 3.0 y el fenómeno Big Data) a la visión espacial de los problemas espaciales.

Hasta el momento solo podemos avanzar algunos obstáculos y resultados experimentales del uso de herramientas 
tecnológicas en el aprendizaje de la geografía. Esto es lo que el profesor Isaac Buzo (capítulo IV, segunda parte) ha mostrado mediante las siglas TAG, es decir, la vertiente de aplicación didáctica de las TIG, en la línea de lo que predica el investigador López Fernández. Con este convencimiento ofrece una síntesis completa de los usos didácticos de las TIG mediante la utilización del GPS, la teledetección, los visores geográficos y globos virtuales, la cartografía digital y los SIG. En cada uno de estos epígrafes ofrece ejemplos concretos de herramientas, entre las que podemos citar el Atlas Digital Escolar en cuya labor de coordinación y ejecución han participado activamente docentes universitarios (María Luisa de Lázaro y Rafael de Miguel) y preuniversitarios (entre los que él mismo se encuentra) de diferentes lugares de España. Como docente de Educación Secundaria conoce los problemas técnicos y humanos que presentan los centros para implantar las tecnologías con carácter definitivo y satisfactorio. Como investigador en este campo de conocimiento finaliza el capítulo con una serie de recomendaciones, siendo una de las más relevantes la simplificación de los usos del software para facilitar el uso generalizado de las tecnologías en las aulas. A esto añade con conocimiento de causa, pues viene impartiendo cursos sobre TIG en diferentes seminarios por España, la necesidad de mejorar la formación docente en aspectos relacionados con las tecnologías de enseñanza en ciencias sociales.

En la última parte del cuarto capítulo, los coordinadores del libro vuelven a retomar el concepto de Andalucía a partir del uso de imágenes para conocer la concepción de este territorio y descentralizar los aprendizajes a otras zonas geográficas. A partir de un análisis de diferentes páginas web oficiales de las diferentes escalas de gobierno andaluzas, han realizado un vaciado que les ha permitido seleccionar ochenta y cinco imágenes que han clasificado en diversas categorías: patrimonio, natural, administración, turismo, transportes, cultura, rural. Para cada una de estas categorías han explicado los atributos más relevantes y los recursos complementarios que aparecen en las webs. Con esa información han pasado una encuesta a más de ochenta alumnos/as del grado de magisterio infantil y primaria de la Universidad de Alicante. Además de conocer la formación previa en geografía, les han pedido que busquen información en dos páginas web (una oficial y otra no oficial) andaluzas para conocer qué criterios rigen su búsqueda, análisis y comprensión de la información icónica mediante el uso de las TICs. Los resultados generales han revelado la ausencia de criterios precisos a la hora de seleccionar imágenes relacionadas con los paisajes de Andalucía y la falta de habilidades de interpretación del paisaje. Así, esta investigación manifiesta que se debe mejorar la formación en el uso de tecnologías entre estudiantes universitarios que se convertirán en docentes en los próximos años.

A modo de conclusión, podemos afirmar que existe un grado creciente de interés por el territorio y las tecnologías entre la sociedad actual. La generalización de dispositivos (móviles, smarpthones, tablets) y los avances técnicos han facilitado la llegada de información geográfica de forma masiva e instantánea. Sobre este contexto es sobre el que han reflexionado los autores que han participado en esta publicación. Todos han mostrado sus investigaciones académicas para responder a las nuevas demandas, haciendo hincapié en aportar rigurosos fundamentos teóricos y metodológicos que permitan tratar los contenidos geográficos que requiere la sociedad para afrontar problemas sociales y ambientales. Su compromiso por mejorar la enseñanza y el aprendizaje de la geografía escolar les ha llevado a relacionar 
sus líneas de investigación con proyectos de innovación, así como la creación y difusión de materiales o propuestas didácticas que orienten la práctica escolar. Por todo ello, considero que es un libro recomendable para estudiantes de grado y posgrado preocupados por la enseñanza y la innovación didáctica en el campo de las Ciencias Sociales.

Prof. Diego García Monteagudo ${ }^{1}$ Profesor Asociado, Departamento de Didáctica de las Ciencias Experimentales y

Sociales, Facultat de Magisteri, Universitat de València. diegar4@alumni.uv.es

1 El presente trabajo forma parte del proyecto Interuniversitario "Competencias sociales para una ciudadanía democrática: análisis, desarrollo y evaluación" (COMDEMO-EDU2015-65621-C3-1-R) financiado por el Ministerio de Economía y Competitividad del gobierno de España. 